\title{
Morphology-controlled nonaqueous synthesis of anisotropic lanthanum hydroxide nanoparticles
}

\author{
Igor Djerdj ${ }^{\mathrm{a}, \mathrm{d}}$, Georg Garnweitner ${ }^{\mathrm{b}}$, Dang Sheng $\mathrm{Su}^{\mathrm{c}}$ and Markus Niederberger ${ }^{\mathrm{a}, *}$
}

\author{
${ }^{a}$ ETH Zürich, Department of Materials, Wolfgang-Pauli-Strasse 10, 8093 Zürich, Switzerland \\ ${ }^{\mathrm{b}}$ Max Planck Institute of Colloids and Interfaces, Research Campus Golm, D-14424 Potsdam, Germany \\ 'Department of Inorganic Chemistry, Fritz-Haber-Institute of the Max-Planck-Society, Faradayweg 4-6, \\ D-14195 Berlin, Germany \\ ${ }^{\mathrm{d}}$ Department of Physics, Faculty of Science, University of Zagreb, Bijenička 32, P.O. Box 331, 10002 \\ Zagreb, Croatia \\ *Corresponding author. Fax: +4144 632 1101, E-mail address: markus.niederberger@mat.ethz.ch (M. Niederberger).
}

\begin{abstract}
The preparation of lanthanum hydroxide and manganese oxide nanoparticles is presented, based on a nonaqueous sol-gel process involving the reaction of $\mathrm{La}(\mathrm{O} i \mathrm{Pr})_{3}$ and $\mathrm{KMnO}_{4}$ with organic solvents such as benzyl alcohol, 2-butanone and a 1:1 vol. mixture thereof. The lanthanum manganese oxide system is highly complex and surprising results with respect to product composition and morphology were obtained. In dependence of the reaction parameters, the $\mathrm{La}(\mathrm{OH})_{3}$ nanoparticles undergo a shape transformation from short nanorods with an average aspect ratio of 2.1 to micron-sized nanofibers (average aspect ratio is more than 59.5). Although not directly involved, $\mathrm{KMnO}_{4}$ plays a crucial role in determining the particle morphology of $\mathrm{La}(\mathrm{OH})_{3}$. The reason lies in the fact that $\mathrm{KMnO}_{4}$ is able to oxidize the benzyl alcohol to benzoic acid, which presumably induces the anisotropic particle growth in [001] direction upon preferential coordination to the $\pm(100), \pm(010)$ and $\pm(-110)$ crystal facets. By adjusting the molar $\mathrm{La}(\mathrm{O} i \mathrm{Pr})_{3}$-to- $\mathrm{KMnO}_{4}$ ratio as well as by using the appropriate solvent mixture it is possible to tailor the morphology, phase purity and microstructure of the $\mathrm{La}(\mathrm{OH})_{3}$ nanoparticles. Postsynthetic thermal treatment of the sample containing $\mathrm{La}(\mathrm{OH})_{3}$ nanofibers and $\beta-\mathrm{MnOOH}$ nanoparticles at the temperature of $800^{\circ} \mathrm{C}$ for $8 \mathrm{~h}$ yielded polyhedral $\mathrm{LaMnO}_{3}$ and worm-like $\mathrm{La}_{2} \mathrm{O}_{3}$ nanoparticles as final products.
\end{abstract}

Keywords: Nonaqueous synthesis; Solvothermal synthesis; Lanthanum hydroxide nanofibers; Transmission electron microscopy

\section{Introduction}

Lanthanides have been applied in various fields due to their electronic configuration ( $4 f$ electrons) and lanthanide-based materials have interesting magnetic, optical, electrical, and nuclear properties. They have been widely used in phosphors for fluorescent lighting [1] and [2], semiconductors [3] and [4], or time-resolved fluorescence labels for biological detection [5]. Lanthanum, the lightest element among the lanthanides, has been extensively examined as oxide, hydroxide, phosphate, or oxychloride for optical [6] and [7], solid electrolyte [8], catalytic [9], [10] and [11], and sorbent properties [12]. Especially, lanthanum hydroxide $\mathrm{La}(\mathrm{OH})_{3}$ has been used as an intermediate step in the synthesis of the oxides or sulfides through dehydration or sulfuration, because that approach is straightforward [13]. Hydroxyl groups may also act as 
active sites for surface grafting through condensation reactions of organic or biological reagents [14]. Recently, research was focused on two main features of $\mathrm{La}(\mathrm{OH})_{3}$, namely its catalytic and sorbent properties. Concerning catalysis, $\mathrm{La}(\mathrm{OH})_{3}$ as well as $\mathrm{La}_{2} \mathrm{O}_{3}$ is used as support for metals such as rhodium and platinum that are active for different reactions [11]. The major objective in terms of catalysis is to improve the catalytic capability, which can be achieved by the enlargement of the catalyst surface area, or/and by doping with selected metals like $\mathrm{Ba}, \mathrm{Pb}$ or $\mathrm{Cu}$ [13].

It has been reported that $\mathrm{La}_{2} \mathrm{O}_{3}$ and $\mathrm{La}(\mathrm{OH})_{3}$ are very sensitive to atmospheric conditions. When they are exposed to ambient carbon dioxide under ordinary conditions of temperature and pressure, the process of carbonation occurs, leading to the formation of surface carbonates or hydroxycarbonates [12] and [15]. If the reaction temperature is higher than $450{ }^{\circ} \mathrm{C}$, chemisorption of $\mathrm{CO}_{2}$ results in $\mathrm{La}_{2} \mathrm{O}_{2} \mathrm{CO}_{3}$. The influence of carbonates and oxycarbonates on the catalytic performances has been discussed for the oxidative coupling of methane reaction [16].

Material properties can often be significantly improved by producing particles in the nanometric range with controlled shape and size. Moreover, designing systems with lower dimensionality like nanofibers, nanowires, nanobelts or nanorods is of great importance due to the possible novel properties induced by the reduced dimensionality. In such systems carrier motion is restricted in two directions implying that they exhibit significant electron-transport properties different from the bulk material [17]. In this context the synthesis of $\mathrm{La}(\mathrm{OH})_{3}$ compounds with quasi-one-dimensional morphology is important. Literature on the synthesis of $\mathrm{La}(\mathrm{OH})_{3}$ nanoparticles with different morphologies is however scarce. The formation of $\mathrm{La}(\mathrm{OH})_{3}$ nanotubes [18], nanowires, nanosheets, nanorods [17] and nanobelts [19] has been reported. The synthesis of these nanostructures was based on the preparation of rare earth hydroxide colloidal precipitates and the subsequent hydrothermal treatment at a designated temperature. The particle morphology was tuned by changing experimental parameters, particularly $\mathrm{pH}$ value of the aqueous solution [17] and [18]. In addition to these template-free routes to $\mathrm{La}(\mathrm{OH})_{3}$ nanostructures, the synthesis of stable $\mathrm{La}(\mathrm{OH})_{3}$ nanoparticles in water by performing hydrolysis and condensation reactions of lanthanum cations in the presence of block copolymers was reported, too. The asymmetry degree of the copolymer influenced both the size and the shape of the particles [20].

All these solution routes were performed in water as solvent. To the best of our knowledge, crystalline $\mathrm{La}(\mathrm{OH})_{3}$ nanoparticles and nanostructures have not yet been synthesized using a nonaqueous sol-gel route. In comparison to reactions in aqueous media, the synthesis of nanoparticles in organic solvents seems to provide better control over particle size, shape, crystallinity, and surface properties [21], [22], [23] and [24].

In this work, we present a nonaqueous sol-gel route to $\mathrm{La}(\mathrm{OH})_{3}$ nanoparticles with a variety of particle morphologies ranging from nanorods to nanofibers. The solvothermal reaction between lanthanum(III) isopropoxide and either benzyl alcohol, 2-butanone or a mixture thereof in the presence of $\mathrm{KMnO}_{4}$ resulted in the formation of lanthanum hydroxide nanoparticles as main phase. The morphology, phase purity and crystallinity of the final products are controlled by simple variation of the $\mathrm{KMnO}_{4}$ concentration without the use of any additional ligands or templates. Thermal treatment of the sample containing $\mathrm{La}(\mathrm{OH})_{3}$ nanofibers and $\beta-\mathrm{MnOOH}$ nanoparticles resulted in the formation of polyhedral $\mathrm{LaMnO}_{3}$ and worm-like $\mathrm{La}_{2} \mathrm{O}_{3}$ nanoparticles as final products. All the samples were investigated by powder X-ray diffraction (XRD), scanning electron microscopy (SEM), transmission electron microscopy (TEM), combined high-resolution transmission electron microscopy (HRTEM), selected area electron diffraction (SAED) and energy-dispersive X-ray (EDX) analysis. Fourier transform infrared spectroscopy (FTIR) was used to investigate the organic and inorganic impurities attached to $\mathrm{La}(\mathrm{OH})_{3}$ as well as to evidence the presence of $\mathrm{OH}$ groups. Analysis of the organic species in the 
final reaction mixture by ${ }^{1} \mathrm{H}$ and ${ }^{13} \mathrm{C}$ nuclear magnetic resonance (NMR) was performed in order to elucidate possible reaction mechanisms. We propose a model for the anisotropic growth of the $\mathrm{La}(\mathrm{OH})_{3}$ nanoparticles taking the role of the solvents as well as of $\mathrm{KMnO}_{4}$ into account.

\section{Experimental Details}

\subsection{Materials}

Lanthanum(III) isopropoxide (99.99+\%), potassium permanganate (99.99+\%), anhydrous benzyl alcohol (99.8\%), and 2-butanone (99.5+ HPLC grade) were obtained from Aldrich and used asreceived. The solvothermal treatment was performed in Parr acid digestion bombs with $45 \mathrm{ml}$ Teflon cups.

\subsection{Synthesis}

All synthesis procedures were carried out in a glovebox $\left(\mathrm{O}_{2}\right.$ and $\left.\mathrm{H}_{2} \mathrm{O}<0.1 \mathrm{ppm}\right)$. The synthesis procedure was as follows: A mixture of $158.1 \mathrm{mg}$ of $\mathrm{La}(\mathrm{OiPr})_{3}(0.5 \mathrm{mmol})$ and $79.0 \mathrm{mg}$ of $\mathrm{KMnO}_{4}(0.5 \mathrm{mmol})$ was added to $20 \mathrm{~mL}$ of the organic solvents [benzyl alcohol, 2-butanone or a 1:1 vol. mixture thereof $(10 \mathrm{~mL}$ benzyl alcohol and $10 \mathrm{~mL} \mathrm{2-butanone})]$. In the case of the solvent mixture, the molar concentration of $\mathrm{KMnO}_{4}$ was varied from $0.5,0.25,0.125$ to $0 \mathrm{mmol}$, keeping the molar concentration of $\mathrm{La}(\mathrm{O} i \mathrm{Pr})_{3}$ constant at $0.5 \mathrm{mmol}$. The reaction mixture was transferred into a Teflon cup of $45 \mathrm{~mL}$ inner volume, slid into a steel autoclave, and carefully sealed. The autoclave was taken out of the glovebox and heated in a furnace at $200{ }^{\circ} \mathrm{C}$ for 3 days. The resulting brown suspensions were centrifuged in order to separate the precipitate from the mother liquid. Excess organic impurities were removed by repeated washing steps in $10 \mathrm{~mL}$ of high-grade purity ethanol and chloroform and subsequently dried in air at $60{ }^{\circ} \mathrm{C}$. Calcination of selected samples was performed at $800^{\circ} \mathrm{C}$ for $8 \mathrm{~h}$ in air.

\subsection{Characterization}

X-ray powder diffraction (XRD) patterns were measured in reflection mode with CuK $\alpha$ radiation on a Bruker D8 diffractometer equipped with a scintillation counter. The instrumental contribution to the peak broadening caused by instrumental aberrations was removed by the deconvolution method with highly crystalline $\alpha-\mathrm{Al}_{2} \mathrm{O}_{3}$ as a standard. Scanning electron microscopy (SEM) characterization including energy-dispersive X-ray (EDX) microanalysis was performed with JEOL-JEM-6330F microscope operating at $15 \mathrm{kV}$. Transmission electron microscopy (TEM) measurement was performed on a Zeiss EM $912 \Omega$ instrument at an acceleration voltage of $120 \mathrm{kV}$, while high-resolution transmission electron microscopy (HRTEM) characterization was done using a Philips CM200-FEG microscope ( $200 \mathrm{kV}, C s=1.35$ $\mathrm{mm}$ ) equipped with a field emission gun. The samples for TEM characterization in a plane-view were prepared in a way that one drop of the dispersion of as-synthesized powder in ethanol was deposited onto a copper grid covered by an amorphous carbon film. To prevent agglomeration of nanoparticles the copper grid was placed on a filter paper at the bottom of a Petri dish. For crosssectional TEM the samples were prepared using the ultramicrotomy procedure. The powder was added to gelatine capsule and subsequently filled with LRWhite resin. The capsules were dried for three days at $60{ }^{\circ} \mathrm{C}$ to allow polymerization. Afterwards, the capsules were trimmed to form the trapezoid. Ultrathin sections of approximately $50 \mathrm{~nm}$ thicknesses were cut using the ultramicrotome (UCT Leica) and mounted on copper grids. Fourier transform infrared (FTIR) investigations were performed on a Perkin-Elmer 2000 FTIR spectrometer. The formation mechanism for the metal hydroxide nanostructures was elucidated by characterization of the organic byproducts. The final reaction mixture was subjected to NMR and gas chromatography analyses after removal of the inorganic product by centrifugation. ${ }^{1} \mathrm{H}$-BB-decoupled ${ }^{13} \mathrm{C} \mathrm{NMR}$ measurements were performed on a Bruker DPX 400 spectrometer at $100 \mathrm{MHz}$, at a sample spinning rate of $20 \mathrm{~Hz}$ and with a ZG30 pulse program. 
The structural and microstructural parameters were extracted using Rietveld refinement [25] with the program Fullprof [26]. The scale factor, the background coefficients, the zero point of the detector and the unit-cell parameters were simultaneously refined, followed by the refinement of the Gaussian half-width parameters, $U, V, W$, and the Lorentzian half-width parameters, $X, Y$. These parameters define the diffraction profile function, which was chosen to be the modified Thompson-Cox-Hastings pseudo-Voigt (T-C-H pV) [27], making the size analysis straightforward. In our approach we assumed that the line broadening of the deconvoluted profile was a result of the small crystallite size only, and therefore the values of half-width parameters $U, V, W$ and $X$ were kept constant at instrumental values determined by the $\alpha-\mathrm{Al}_{2} \mathrm{O}_{3}$ standard. Due to the observed anisotropic size broadening, size analysis of such anisotropically broadened reflections was performed by fitting independently their size-like parameters. The background was taken to be the polynomial function of $2 \theta$ of the 5 th order, because only in this case the best background modelling was obtained. The refinement incorporated weights $w_{i}$ based on the observed step intensities $Y_{i}, w_{i}=1 / Y_{i}$. The refinement was continued until the shift in any parameter, $\Delta x_{i}$, was less than one third of its estimated standard deviation, $\sigma_{i}$. The quality of Rietveld refinement was evaluated in terms of the discrepancy factor (profile-weighted residual error), $R_{w p}$, Bragg discrepancy factor $R_{B}$ and the goodness-of-fit indicator, GoF.

\section{Results and discussion}

The lanthanum manganese oxide system was investigated by reacting $\mathrm{La}(\mathrm{O} i \mathrm{Pr})_{3}$ and $\mathrm{KMnO}_{4}$ with either benzyl alcohol (BA), 2-butanone (BUT), or a mixture of both solvents (BA+BUT) in the vol. ratio of 1:1. Furthermore, the influence of the $\mathrm{KMnO}_{4}$ concentration on the particle morphology of $\mathrm{La}(\mathrm{OH})_{3}$ was monitored in detail for the mixed BA+BUT system by variation of the molar ratios of $\mathrm{La}(\mathrm{O} i \mathrm{Pr})_{3}$-to- $\mathrm{KMnO}_{4}$ as follows: $1: 1$ [denoted as $\mathrm{BA}+\mathrm{BUT}(1: 1)$ ], 1:0.5 [BA+BUT (1:0.5)], 1:0.25 [BA+BUT (1:0.25)], $1: 0.125$ [BA+BUT (1:0.125)] and 1:0 [BA+BUT (1:0)].

X-ray powder diffraction (XRD) patterns of the samples obtained are shown in Fig. 1. In all cases most reflections can be well indexed in the hexagonal $\mathrm{La}(\mathrm{OH})_{3}$ structure with the space group $P 6_{3} / m$ (ICDD PDF\#36-1481). The corresponding Miller indices are denoted in the uppermost diffractogram for BA+BUT (1:1), i.e., the sample obtained in a mixture of BA+BUT with a $\mathrm{La}(\mathrm{O} i \mathrm{Pr})_{3}$-to- $\mathrm{KMnO}_{4}$ ratio of 1 . One can clearly see that in addition to $\mathrm{La}(\mathrm{OH})_{3}$ as major phase all samples, except the sample BA+BUT (1:0.5), contain crystalline byproducts.

The XRD pattern of the sample BA+BUT (1:1) shows additional reflections at $2 \theta$ positions of $19.23^{\circ}, 33.75^{\circ}$ and $37.95^{\circ}$, which can be assigned to $\beta-\mathrm{MnOOH}$, mineralogical name Feitknechtite (ICDD PDF\#18-804) [28]. According to the ICDD card this compound crystallizes in the tetragonal crystal system with the lattice constants $a=8.6 \AA$ and $c=9.3 \AA$, however with unknown space group. The reaction in pure benzyl alcohol [BA (1:1)] yielded as minor phase $\mathrm{Mn}_{3} \mathrm{O}_{4}$-Hausmannite, tetragonal system, space group I4 1 amd (ICDD PDF\#24-734). The strongest well-resolved reflections of $\mathrm{Mn}_{3} \mathrm{O}_{4}$-Hausmannite are denoted in the XRD pattern with their Miller indices 101, 103, and 211. These results clearly prove the influence of the solvents on the product composition. While all other synthesis conditions are similar, the reaction in BA leads to $\mathrm{Mn}_{3} \mathrm{O}_{4}$-Hausmannite as minor phase, whereas in BA+BUT $(1: 1) \beta-\mathrm{MnOOH}$ represents the byproduct. When the synthesis is performed in pure 2-butanone [BUT (1:1)] and in the mixture of benzyl alcohol and 2-butanone with molar $\mathrm{La}(\mathrm{O} i \mathrm{Pr})_{3}$-to- $\mathrm{KMnO}_{4}$ ratios of 1:0.25 [BA+BUT (1:0.25)] and 1:0 [BA+BUT (1:0)], the final products contain $\mathrm{LaCO}_{3} \mathrm{OH}$ as a minor phase. This compound crystallizes in the orthorhombic system with the space group $C 222_{1}$ and with the unit-cell parameters $a=21.891 \AA, b=12.639 \AA$ and $c=10.047 \AA$ (ICDD PDF\#29-744). The three strongest reflections of $\mathrm{LaCO}_{3} \mathrm{OH}$ are indexed 332, 60 , and 002 in the respective powder patterns. A qualitative comparison of the intensity of the strongest 600 reflections clearly shows that the fraction of $\mathrm{LaCO}_{3} \mathrm{OH}$ is the largest in BUT (1:1), significantly smaller in $\mathrm{BA}+\mathrm{BUT}(1: 0.25)$, and finally its presence in BA+BUT (1:0) is found only in traces. 


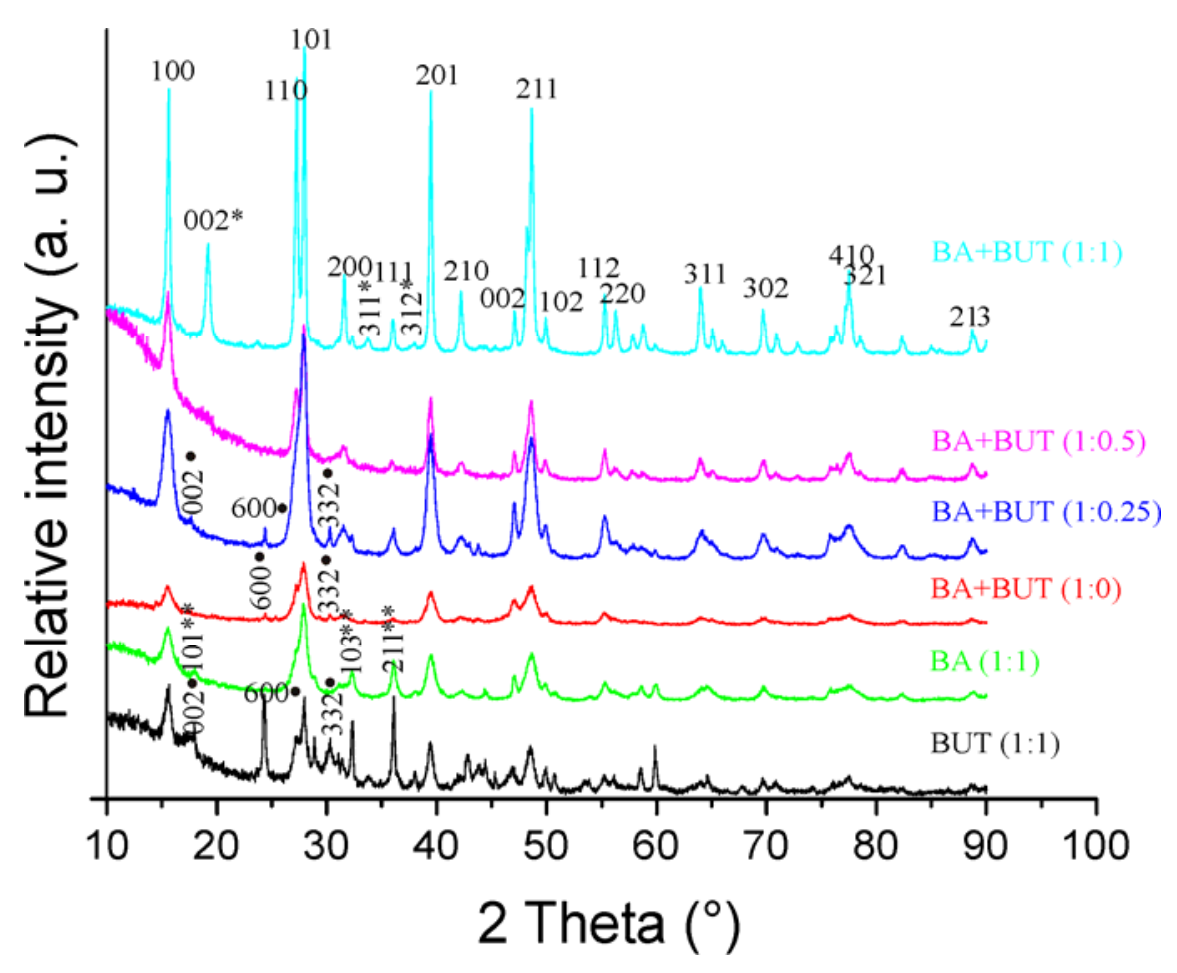

Figure 1. XRD patterns of the samples in dependence of the solvent (BA, BUT and a mixture of $\mathrm{BA}+\mathrm{BUT})$ and the $\mathrm{La}(\mathrm{O} i \mathrm{Pr})_{3}$-to- $\mathrm{KMnO}_{4}$ ratio $(1: 1,1.0 .5,1: 0.25$ and 1:0). In addition to the Miller indices of the main $\mathrm{La}(\mathrm{OH})_{3}$ phase, the three strongest reflections of identified minor phases are also denoted: *$\beta-\mathrm{MnOOH}, * *-\mathrm{Mn}_{3} \mathrm{O}_{4}$ (Hausmannite), $\bullet-\mathrm{LaCO}_{3} \mathrm{OH}$.

The crystal structure was refined for $\mathrm{La}(\mathrm{OH})_{3}$ and $\mathrm{Mn}_{3} \mathrm{O}_{4}$ only, while for the other compounds refinement was not possible due to the unknown space group $(\beta-\mathrm{MnOOH})$, or missing fractional atomic coordinates $\left(\mathrm{LaCO}_{3} \mathrm{OH}\right)$. The results of Rietveld refinement are summarized in Table 1, while the Rietveld refinement plot for the single-phase system BA+BUT (1:0.5) together with the difference curve is displayed in Fig. 2. Visual inspection of the difference curve confirms the good refinement and correct choice of the structural model. The quality of the fit is also estimated numerically in terms of weighted profile factor $R_{\mathrm{wp}}$ [29], whose values are given in the last row of Table 1. The best fit is achieved for the single-phase BA+BUT (1:0.5) XRD pattern, while for the other two-phase systems the $R_{\mathrm{wp}}$ values are higher. This is due to the presence of a second phase, which was not taken into account for refinement. Moreover, the increasing order of $R_{\mathrm{wp}}$ for the systems containing $\mathrm{LaCO}_{3} \mathrm{OH}$ is related to the increase of the $\mathrm{LaCO}_{3} \mathrm{OH}$ fraction. In this way, the $R_{\mathrm{wp}}$ serves as a rough estimate for the quantity of the second phase. The calculated lattice parameters for the hexagonal $\mathrm{La}(\mathrm{OH})_{3}$ structure are also given in Table 1 . The values $a=6.5286 \AA$ and $c=3.8588 \AA$ fit well with ICDD data (ICDD PDF\#36-1481). The slight variation of the calculated lattice parameter values with the synthesis conditions does not show any regularity or functional dependence on some measurable quantity such as crystallite size. Their small mutual differences can be regarded as simply originating from the refinement procedure. The calculated unit-cell volume values also agree well with each other. In addition to the unit-cell parameters calculation, the fractional atomic co-ordinates of $\mathrm{La}$ and $\mathrm{O}$ atoms are extracted, enabling a complete refinement of the $\mathrm{La}(\mathrm{OH})_{3}$ structure. Due to the low electron density of the hydrogen atom, its fractional atomic co-ordinates cannot be determined from the XRD patterns. 
Table 1. Structural data and refinement parameters for $\mathrm{La}(\mathrm{OH})_{3}$ calculated by Rietveld refinement of XRD powder patterns.

\begin{tabular}{|c|c|c|c|c|c|c|}
\hline & $\begin{array}{c}\text { BA+BUT } \\
(1: 1)\end{array}$ & $\begin{array}{c}\text { BA+BUT } \\
(1: 0.5)\end{array}$ & $\begin{array}{c}\text { BA+BUT } \\
(1: 0.25)\end{array}$ & $\begin{array}{c}\text { BA+BUT } \\
(1: 0)\end{array}$ & BA (1:1) & BUT (1:1) \\
\hline $\begin{array}{c}\text { phase } 1 \\
\text { space group }\end{array}$ & $\begin{array}{c}\mathrm{La}(\mathrm{OH})_{3} \\
P 6_{3} / m(176)\end{array}$ & $\begin{array}{c}\mathrm{La}(\mathrm{OH})_{3} \\
P 6_{3} / m(176)\end{array}$ & $\begin{array}{c}\mathrm{La}(\mathrm{OH})_{3} \\
P 6_{3} / m(176)\end{array}$ & $\begin{array}{c}\mathrm{La}(\mathrm{OH})_{3} \\
P 6_{3} / m(176)\end{array}$ & $\begin{array}{c}\mathrm{La}(\mathrm{OH})_{3} \\
P 6_{3} / m(176)\end{array}$ & $\begin{array}{c}\mathrm{La}(\mathrm{OH})_{3} \\
P 6_{3} / m(176)\end{array}$ \\
\hline lattice & $a=6.532(1)$ & $a=6.528(1)$ & $a=6.517(1)$ & $a=6.524(2)$ & $a=6.515(2)$ & $a=6.534(2)$ \\
\hline parameters & $c=3.8553(4)$ & $c=3.8529(3)$ & $c=3.8530(3)$ & $c=3.857(1)$ & $c=3.854(1)$ & $c=3.856(1)$ \\
\hline$(\AA)$ & $\gamma=120^{\circ}$ & $\gamma=120^{\circ}$ & $\gamma=120^{\circ}$ & $\gamma=120^{\circ}$ & $\gamma=120^{\circ}$ & $\gamma=120^{\circ}$ \\
\hline $\begin{array}{c}\text { cell volume } \\
\qquad\left(\AA^{3}\right)\end{array}$ & $142.45(2)$ & $142.21(2)$ & $141.72(2)$ & $142.2(1)$ & $141.7(1)$ & $142.6(1)$ \\
\hline \multicolumn{7}{|l|}{ La site } \\
\hline$x$ & 0.333 & 0.333 & 0.333 & 0.333 & 0.333 & 0.333 \\
\hline$y$ & 0.667 & 0.667 & 0.667 & 0.667 & 0.667 & 0.667 \\
\hline$z$ & 0.250 & 0.250 & 0.250 & 0.250 & 0.250 & 0.250 \\
\hline \multicolumn{7}{|l|}{ O site } \\
\hline$x$ & $0.340(3)$ & $0.340(3)$ & $0.348(2)$ & $0.346(4)$ & $0.336(5)$ & $0.36(1)$ \\
\hline$y$ & $0.277(3)$ & $0.289(3)$ & $0.285(2)$ & $0.284(4)$ & $0.267(5)$ & $0.30(1)$ \\
\hline$z$ & 0.250 & 0.250 & 0.250 & 0.250 & 0.250 & 0.250 \\
\hline $\begin{array}{c}\text { isotropic } \\
\text { average } \\
\text { crystallite size } \\
\text { (nm) }\end{array}$ & 31.8 & 14.8 & 8.9 & 7.4 & 7.8 & 12.3 \\
\hline $\begin{array}{c}\text { special } \\
\text { reflection } \\
\text { broadening }\end{array}$ & 60.8 & 53.1 & 23.6 & - & 22.0 & - \\
\hline \multicolumn{7}{|l|}{$D_{002}(\mathrm{~nm})$} \\
\hline $\begin{array}{l}\text { No. of } \\
\text { reflections }\end{array}$ & 52 & 52 & 52 & 52 & 52 & 52 \\
\hline phase 2 & $\beta-\mathrm{MnOOH}$ & - & $\mathrm{LaCO}_{3} \mathrm{OH}$ & $\mathrm{LaCO}_{3} \mathrm{OH}$ & $\begin{array}{c}\mathrm{Mn}_{3} \mathrm{O}_{4} \\
\text { (Hausmannite) }\end{array}$ & $\mathrm{LaCO}_{3} \mathrm{OH}$ \\
\hline space group & unknown & & $C 222_{1}(20)$ & $C 222_{1}(20)$ & I $4_{1} /$ amd (141) & $C 222_{1}(20)$ \\
\hline \multirow{5}{*}{$\begin{array}{c}\text { lattice } \\
\text { parameters } \\
(\AA)\end{array}$} & $a=8.6$ & & $a=21.891$ & $a=21.891$ & & $a=21.891$ \\
\hline & $\begin{array}{l}a-0.0 \\
c=93\end{array}$ & & $b=12.639$ & $b=12.639$ & $a=5.761(3)$ & $b=12.639$ \\
\hline & $\begin{array}{c}c-9.3 \\
\text { (ICDD PDF }\end{array}$ & & $c=10.047$ & $c=10.047$ & $c=9.446(5)$ & $c=10.047$ \\
\hline & (ICDD PDT & & (ICDD PDF & (ICDD PDF & & (ICDD PDF \\
\hline & (+10-004) & & \#29-744) & \#29-744) & & \#29-744) \\
\hline $\begin{array}{c}\text { cell volume } \\
\qquad\left(\AA^{3}\right) \\
\text { average }\end{array}$ & 687.83 & & 2779.81 & 2779.81 & $313.4(3)$ & 2779.81 \\
\hline $\begin{array}{l}\text { crystallite size } \\
\text { (nm) }\end{array}$ & & & & & 18.3 & \\
\hline $\begin{array}{l}\text { No. of } \\
\text { reflections }\end{array}$ & & & & & 46 & \\
\hline $\begin{array}{l}\text { No. of profile } \\
\text { points }\end{array}$ & 2668 & 2668 & 2668 & 2668 & 2668 & 2668 \\
\hline $2 \theta$ step size & 0.03 & 0.03 & 0.03 & 0.03 & 0.03 & 0.03 \\
\hline$R_{\mathrm{wp}}(\%)$ & 22.9 & 12.4 & 16.1 & 18.3 & 17.8 & 29.0 \\
\hline
\end{tabular}




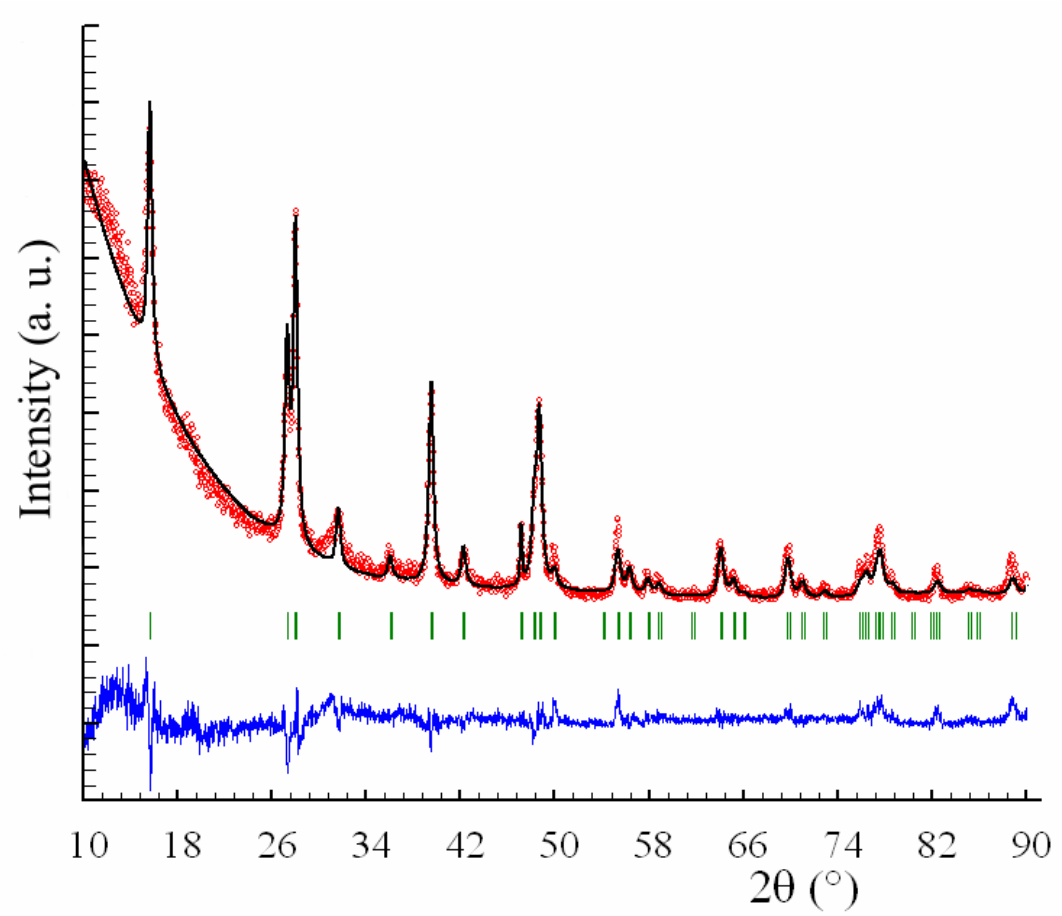

Figure 2. Rietveld refinement plot for $\mathrm{La}(\mathrm{OH})_{3}$ in the BA+BUT (1:0.5) sample. The observed intensity data (red) are plotted in the upper field. The calculated pattern (black) is shown in the same field as a solid-line curve. The difference curve (blue) is shown in the lower field. The short vertical bars in the middle field indicate the positions of the Bragg reflections of $\mathrm{La}(\mathrm{OH})_{3}$.

For the Rietveld refinement, the sample synthesized in pure BA was considered as a two-phase system. Besides $\mathrm{La}(\mathrm{OH})_{3}$, the $\mathrm{Mn}_{3} \mathrm{O}_{4}$-Hausmannite was also refined, and its calculated lattice parameters are $a=5.761 \AA$ and $c=9.446 \AA$. Applying the procedure of Hill and Howard [30], [31] and [32], the weight fractions (wt.\%) of the two crystalline components were obtained and comprise 77.7 wt. $\%$ for $\mathrm{La}(\mathrm{OH})_{3}$ and $22.3 \mathrm{wt} \% \%$ for $\mathrm{Mn}_{3} \mathrm{O}_{4}$.

A qualitative analysis of reflection broadening in Fig. 1 already shows the influence of the isotropic crystallite size. However, a quantitative analysis of the reflection broadening in terms of full-width at half-maximum (FWHM) points to the presence of anisotropic broadening (anisotropic crystallite size), which is in accordance with the morphology of the $\mathrm{La}(\mathrm{OH})_{3}$ nanoparticles (see below). Fig. 3 displays the variation of the FWHM in dependence of the diffraction angle $2 \theta$, extracted from the XRD pattern of the single-phase $\mathrm{La}(\mathrm{OH})_{3}$ sample [BA+BUT (1:0.5)]. The plot indicates that the 002 reflection is considerably narrower $(\mathrm{FWHM}=0.2)$ than all the other peaks (FWHM in the range of 0.4-0.6), pointing to an anisotropic shape of the crystallites with [001] as the preferred growth axis. Considering the nanofiber morphology (see TEM results below), this observation is consistent with the small crystallite size in two dimensions across the nanofiber and the larger crystallite size along the nanofiber axis. Similar findings have already been reported for CdTe nanowires [33]. Based on our FWHM analysis, we assumed that with the exception of 002 all the other reflections are equally broadened (isotropic case). Accordingly, reflection 002 was treated in FULLPROF subroutine as a special case. The whole broadening analysis was performed assuming that the line broadening of the deconvoluted profile occurs only due to the small crystallite effect, neglecting the presence of lattice microstrain. The results of the crystallite size calculation are also presented in Table 1. Comparing the isotropic crystallite sizes of the $\mathrm{La}(\mathrm{OH})_{3}$ samples synthesized in a mixture of $\mathrm{BA}+\mathrm{BUT}$ with different $\mathrm{La}(\mathrm{O} i \mathrm{Pr})_{3}$-to- $\mathrm{KMnO}_{4}$ ratios, one can notice that the average crystallite size decreases from 31.8 to $7.4 \mathrm{~nm}$ with decreasing the molar fraction of $\mathrm{KMnO}_{4}$. The same trend occurs with the crystallite size measured along the [001] direction. In 
addition to the $\mathrm{KMnO}_{4}$ concentration, also the solvent influences the final morphology of the $\mathrm{La}(\mathrm{OH})_{3}$ nanoparticles, proven by a comparison of the isotropic crystallite sizes of the three samples obtained at a $\mathrm{La}(\mathrm{O} i \mathrm{Pr})_{3}$-to- $\mathrm{KMnO}_{4}$ ratio of 1 in different solvents [BA (1:1), BUT (1:1) and BA+BUT (1:1)]. In BA+BUT (1:1) the size is $31.8 \mathrm{~nm}$, which is much larger than in the other two cases, where the isotropic crystal sizes do not differ much and are rather small (7.8 and $12.3 \mathrm{~nm}$, respectively).

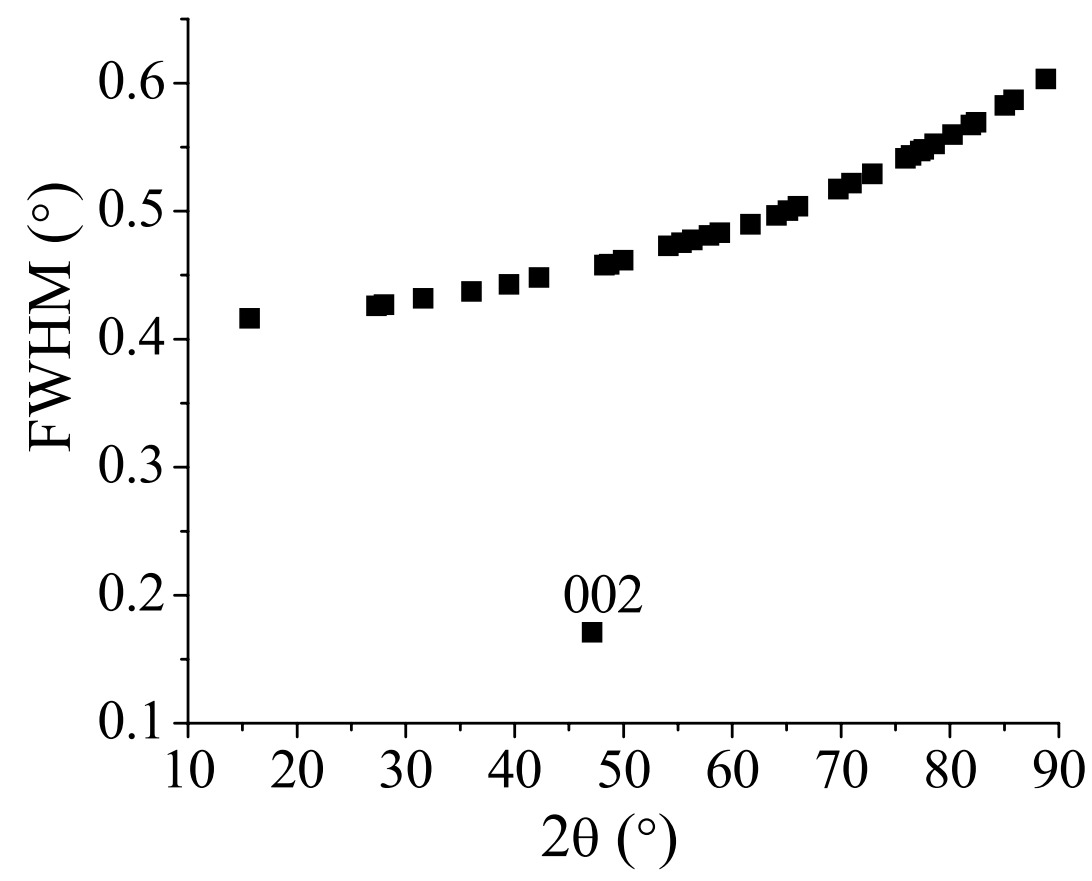

Figure 3. Full-width at half-maximum (FWHM) vs. $2 \theta$ for the reflections of $\mathrm{La}(\mathrm{OH})_{3}$ synthesized in BA+BUT (1:0.5). With the exception of the 002 reflection, all other peaks follow a smooth functional curve.

Representative TEM images of various $\mathrm{La}(\mathrm{OH})_{3}$ nanoparticles are shown in Figs. 4(a)-(f) in dependence of the synthesis conditions. In pure BA two types of nanoparticles located on separated areas on the TEM grid are observed. In addition to $\mathrm{La}(\mathrm{OH})_{3}$ nanorods, small nanoparticles of $\mathrm{Mn}_{3} \mathrm{O}_{4}$ with irregular particle morphology are present, confirming the XRD results. The $\mathrm{La}(\mathrm{OH})_{3}$ nanorods synthesized in pure BUT are considerably shorter (approximately $23 \mathrm{~nm}$ ) in comparison with BA (about $47 \mathrm{~nm}$ ), however with almost similar particle widths (8 and $10 \mathrm{~nm}$, respectively). The average size in terms of particle length and width was estimated by measuring 100 particles in magnified TEM images. The results are summarized in Table 2.

Concerning the $\mathrm{La}(\mathrm{OH})_{3}$ nanoparticles synthesized in a mixture of BA and BUT, it turned out that a change in anisotropy is observed in dependence of the $\mathrm{KMnO}_{4}$ concentration. Decreasing the molar fraction of $\mathrm{KMnO}_{4}$ results in a remarkable transformation of the particle morphology from highly anisotropic nanofibers several $\mu \mathrm{m}$ in length and with an average aspect ratio of more than 59.5 to nanorods just a few nanometers long (average aspect ratio of less than 10). Not only the length of the particles is altered, but also the width decreases from $25 \mathrm{~nm}$ in case of a $\mathrm{La}(\mathrm{O} i \mathrm{Pr})_{3}$-to- $\mathrm{KMnO}_{4}$ ratio of 1 to $7 \mathrm{~nm}$ for the sample without $\mathrm{KMnO}_{4}$. These surprising results underline the importance of the concentration of $\mathrm{KMnO}_{4}$ in determining the particle morphology in this nonaqueous synthesis process. 


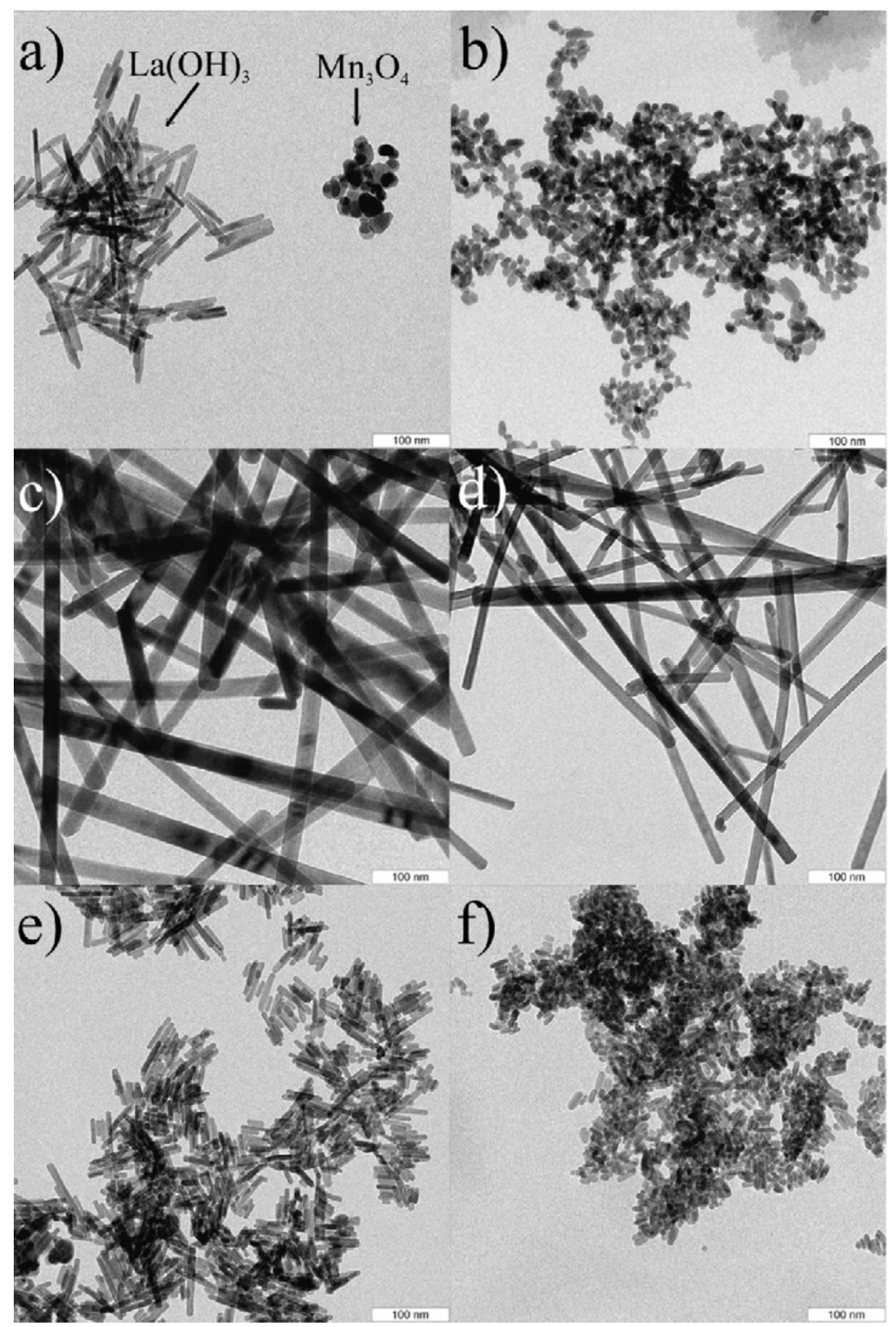

Figure 4.Representative TEM images of the nanoparticles synthesized under various conditions. (a) BA (1:1), (b) BUT (1:1), (c) BA+BUT (1:1), (d) BA+BUT (1:0.5), (e) BA+BUT (1:0.25), (f) BA+BUT (1:0) 
Table 2. Average dimensions (length, width) of $\mathrm{La}(\mathrm{OH})_{3}$ nanostructures measured from TEM images.

\begin{tabular}{lcc}
\hline & $\begin{array}{c}\text { average } \\
\text { nanofiber/nanoro } \\
\text { d length L (nm) }\end{array}$ & $\begin{array}{c}\text { average } \\
\text { nanofiber/nanorod } \\
\text { width W (nm) }\end{array}$ \\
\hline BA (1:1) & 47.2 & 8.5 \\
BUT $(1: 1)$ & 23.5 & 10.9 \\
BA+BUT $(1: 1)$ & $>1 \mu \mathrm{m}$ & 25.7 \\
BA+BUT & $>1 \mu \mathrm{m}$ & 16.8 \\
BA+BUT & 33.2 & 7.8 \\
BA+BUT $(1: 0)$ & 17.9 & 6.8 \\
\hline
\end{tabular}

It is noteworthy that the lateral average dimension of the $\mathrm{La}(\mathrm{OH})_{3}$ nanoparticles measured by TEM agrees well with the isotropic average crystallite size calculated from XRD. This implies that the isotropic broadening of the diffraction peaks relates to the crystallite size in the two dimensions across the nanofibers/nanorods. Figs. 5(a) and (c) show SEM images of the $\mathrm{La}(\mathrm{OH})_{3}$ nanofibers synthesized in BA+BUT (1:1) and (1:0.5). For both synthetic conditions the nanofibers formed show high linearity. The nanofibers synthesized in BA+BUT (1:1) exhibit lengths up to $10 \mu \mathrm{m}$, which is considerably longer compared to the nanofibers obtained in BA+BUT (1:0.5), whose length is in the range of $1-2 \mu \mathrm{m}$. In accordance to TEM, the BA+BUT (1:0.5) nanofibers are narrower than the other sample, however with a much higher tendency to assemble into bundles and sphere-like agglomerates (see Fig. 5(c)). The corresponding EDX spectra of the $\mathrm{La}(\mathrm{OH})_{3}$ nanofibers taken in the SEM mode are shown in Figs. 5(b) and (d). Besides the lines of the constitutive elements La and O, the EDX spectrum of the 1:1 sample has additional lines at 5.90 and $6.46 \mathrm{keV}$, which can be assigned to $\mathrm{MnK} \alpha$ and $\mathrm{MnK} \beta$, giving further evidence for the presence of manganese in the form of crystalline $\beta-\mathrm{MnOOH}$. In contrast to that, the EDX spectrum of the sample (1:0.5) gives no indication for manganese, confirming the phase-purity of the sample.
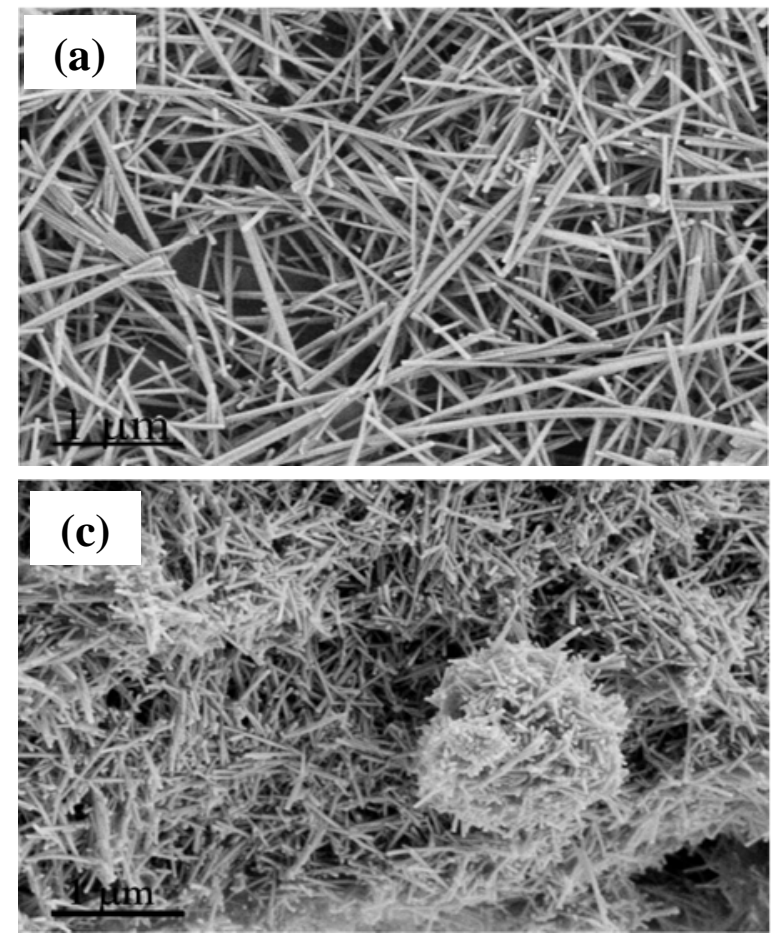

(b)

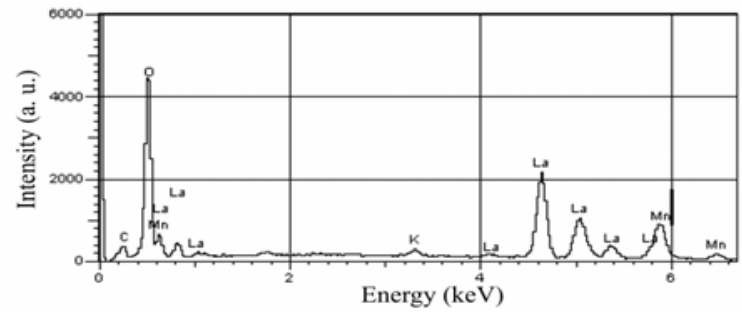

(d)

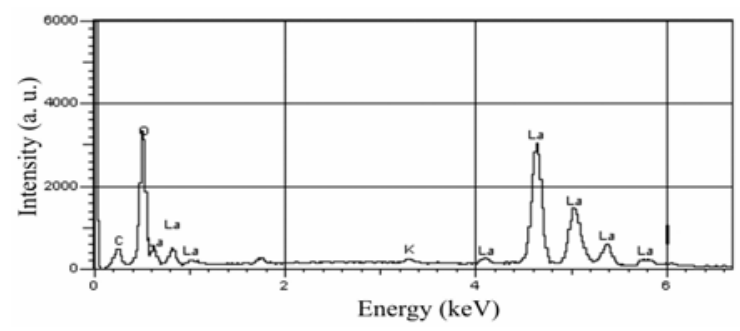

Figure 5. (a) SEM image of the $\mathrm{La}(\mathrm{OH})_{3}$ nanofibers in sample BA+BUT (1:1), (b) corresponding EDX spectrum, (c) SEM image of the $\mathrm{La}(\mathrm{OH})_{3}$ nanofibers in sample BA+BUT (1:0.5), and (d) its EDX spectrum. 
The thickness of the nanofibers seems to be rather small as judged from the HRTEM contrast (see below), exhibiting a morphology similar to that of nanobelts. For samples whose thickness measured parallel to the electron beam does not exceed $15 \mathrm{~nm}$ it is still possible to obtain lattice fringes in HRTEM [34]. Such consideration implies that the thickness of the $\mathrm{La}(\mathrm{OH})_{3}$ nanofibers for which lattice imaging is possible (see below), is less or approximately equal to $15 \mathrm{~nm}$. Further insight into the size and shape of the cross-section of the nanofibers was achieved using cross-sectional TEM. Fig. 6 shows a TEM image recorded in cross-section mode perpendicular to the nanofiber axis for sample BA+BUT (1:1). According to this image, the cross-section of the nanofibers has mostly a rectangular shape with the shorter sides corresponding to the nanofiber thickness and ranging from about 18 to $30 \mathrm{~nm}$. Obviously, the thickness is noticeable smaller than the width, which lies in the range of about $15-48 \mathrm{~nm}$.

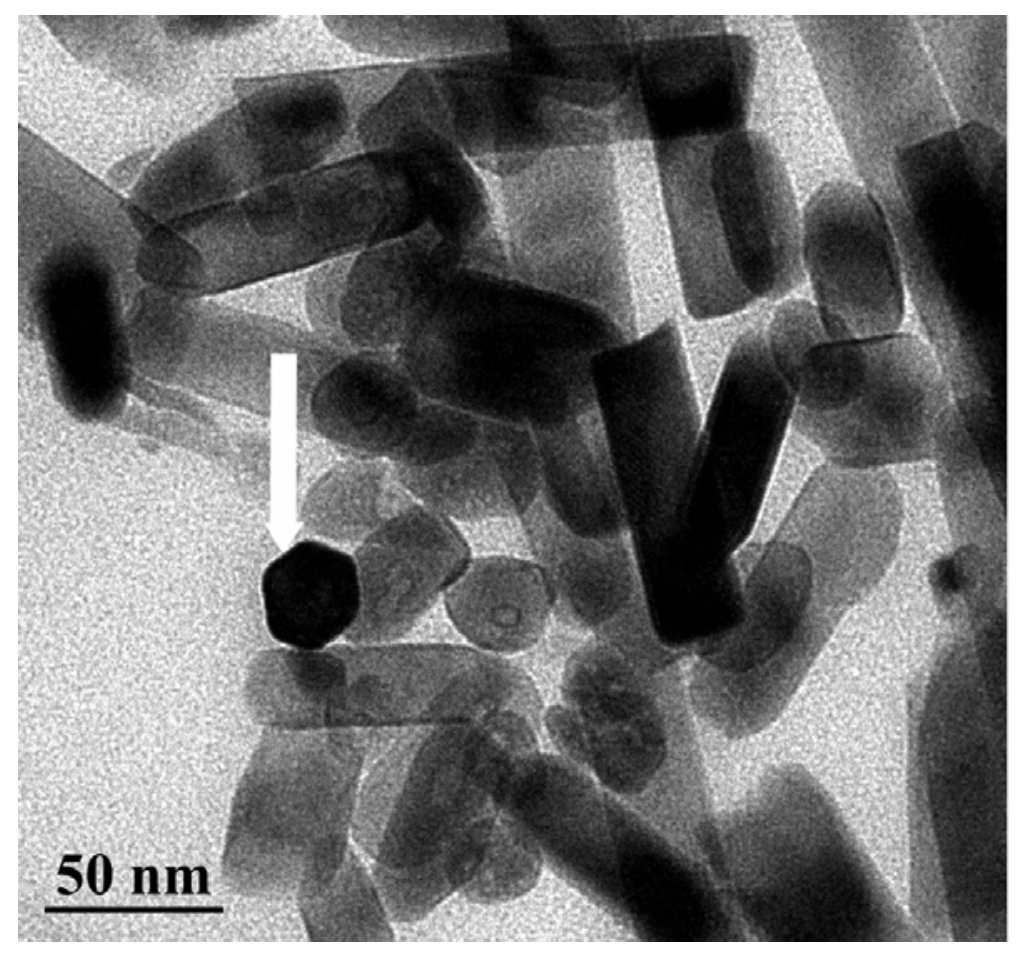

Figure 6.Cross-sectional TEM image of $\mathrm{La}(\mathrm{OH})_{3}$ nanofibers obtained in $\mathrm{BA}+\mathrm{BUT}(1: 1)$.

However, we have to point out that the long nanofibers observed in Fig. 6 are not all displayed in cross section, but rather along the tilted nanofiber axis. Due to the absence of parallel alignment of the nanofibers in 3D space uniform cross-sectional imaging is impossible. However, in some cases, the cross-section mode allows to observe well facetted shapes. Such a nanofiber nicely presented in cross section with a diameter of $29 \mathrm{~nm}$ is denoted with a white arrow in Fig. 6. It has a regular hexagonal shape with the top surface facet $\left(\begin{array}{lll}0 & 0 & 1\end{array}\right)$ and with the side surface facets along the fiber axis $\pm(100), \pm(010), \pm(-110)$.

The structure of the individual nanofibers was further examined by HRTEM. Fig. 7(a) displays a HRTEM image of a part of a $\mathrm{La}(\mathrm{OH})_{3}$ nanofiber in the sample BA+BUT (1:0.5) and imaged in the plane-view. The corresponding power spectrum, shown in the inset, is analyzed and indexed together with the SAED pattern in Fig. 7(b). The indexed spots match well with the XRD patterns of $\mathrm{La}(\mathrm{OH})_{3}$ refined in the hexagonal system with the space group $P 6_{3} / \mathrm{m}$. The nanofiber is oriented along the [010] direction with respect to the electron beam, while its growth direction is along [001], i.e., along the $c$-axis. Such a growth direction, deduced from the analysis of the power spectrum, corroborates the results from cross-sectional TEM with the top surface represented by the well-facetted 001 surface as well as from the anisotropic broadening of the 
sharp 002 reflection in XRD. The HRTEM image also reveals that the surface of the nanofiber is not smooth, which manifests itself as a nonuniform focusing along the fiber axis. According to HRTEM and SAED, it seems that the nanofiber is composed of a single crystal. However, in hexagonal crystal systems and in particular in the case of a one-dimensional particle morphology (nanofibers, nanobelts, nanotubes, nanowires) there is a high probability that twins and stacking faults exist [35], [36] and [37]. Indeed, in the lower part of Fig. 7(a) close to the nanofiber's edge, microtwins are clearly visible. Their presence here and in more general the presence of planar defects within nanofibers imply that nanofiber growth occurred from several nucleation centers resulting in anisotropic defective structure similar as in the case of mesocrystals formation [38]. HRTEM images recorded from other areas of the sample also confirmed the presence of such defect features. By EDX microanalysis the constitutive elements La and $\mathrm{O}$ were detected. Similar to the results obtained in the SEM mode, no traces of Mn were found.
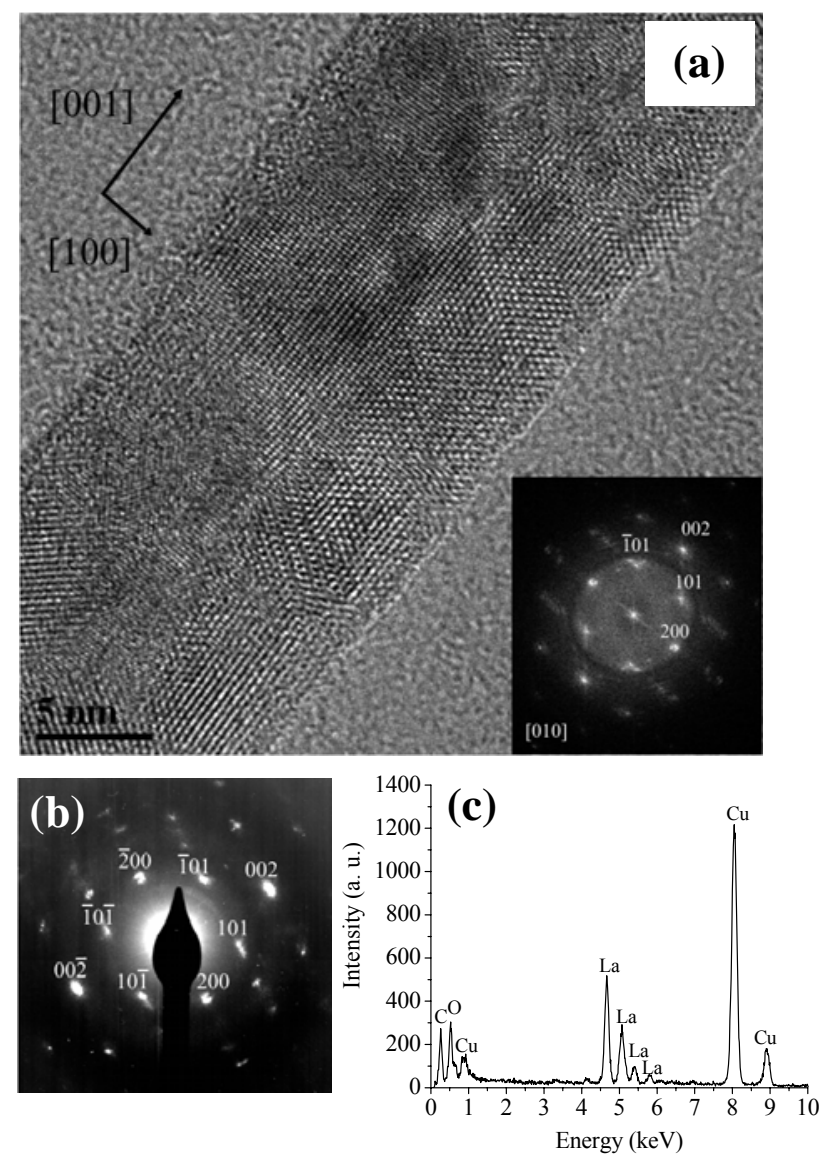

Figure 7. (a) HRTEM image of a part of a $\mathrm{La}(\mathrm{OH})_{3}$ nanofiber in the system $\mathrm{BA}+\mathrm{BUT}(1: 0.5)$ with its power spectrum as inset, (b) corresponding SAED pattern, (c) EDX spectrum.

Fourier transform infrared spectroscopy (FT-IR) was employed as an additional probe to evidence the presence of $\mathrm{OH}$ groups as well as other organic and inorganic species. Fig. 8 displays the FT-IR spectra of the examined samples. An intense and sharp band at $3606 \mathrm{~cm}^{-1}$ and the band observed in the range of $623-636 \mathrm{~cm}^{-1}$ are characteristic of the stretching and bending $\mathrm{OH}$ vibrations of lanthanum hydroxide, respectively [12], [15] and [39]. For all samples excluding BA+BUT (1:1) and (1:0.5), the small and broad band around $3489 \mathrm{~cm}^{-1}$ is present, which can be assigned to $\mathrm{H}$-bridge $\mathrm{O}-\mathrm{H}$ vibration. 


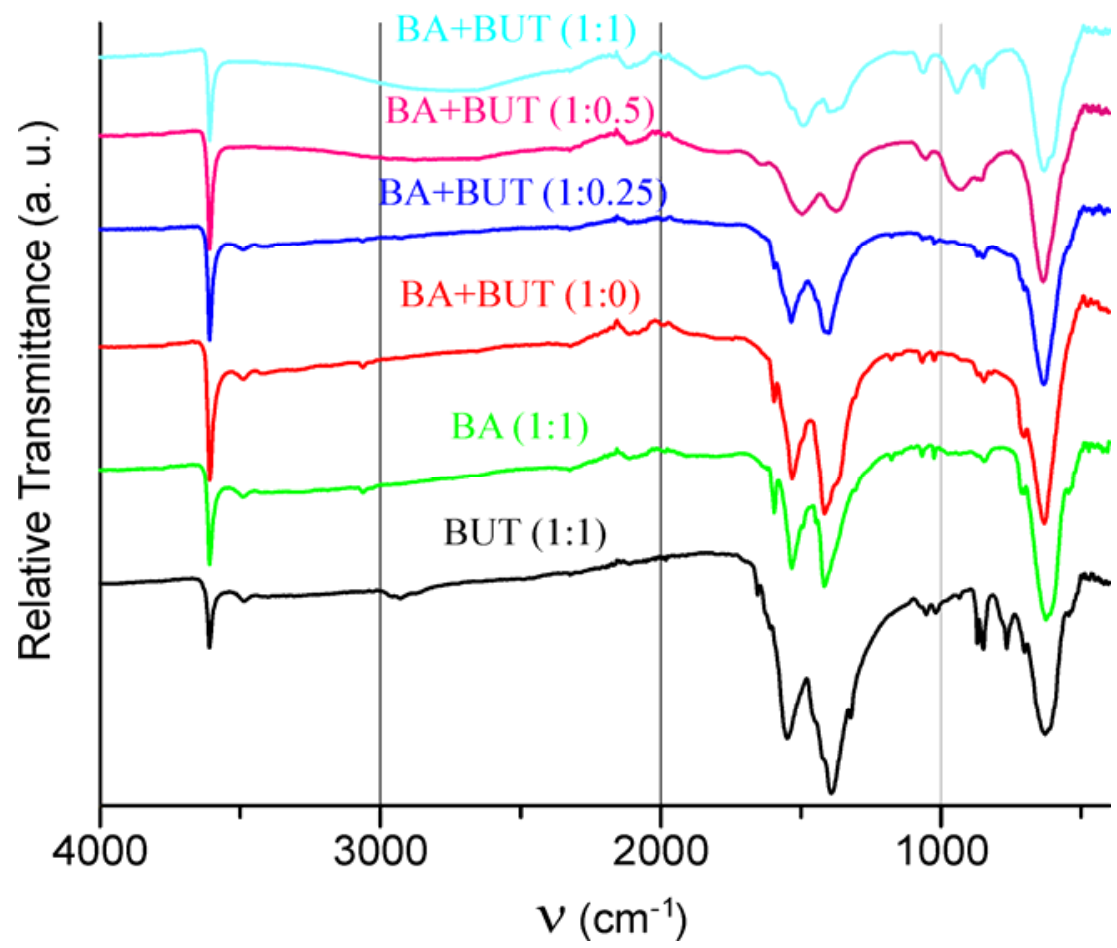

Figure 8.FT-IR spectra of the samples in dependence of the solvents and $\mathrm{La}(\mathrm{O} i \mathrm{Pr})_{3}$-to- $\mathrm{KMnO}_{4}$ ratio.

The most interesting range regarding the various surface adsorbed species is between 1200 and $1600 \mathrm{~cm}^{-1}$. However, it is difficult to unambiguously assign all the bands present, because the carbonate peaks [15], the vibrations of aromatic rings [40] as well as $\mathrm{O}-\mathrm{C}-\mathrm{O}$ modes of benzoate [41] all appear within this area. In the samples BUT (1:1), BA (1:1), BA+BUT (1:0) and BA+BUT (1:0.25), the two intense bands are observed in the regions of $1373-1413 \mathrm{~cm}^{-1}$ and $1490-1548 \mathrm{~cm}^{-1}$, corresponding to the $v_{3}$ vibration of $\mathrm{CO}_{3}{ }^{2-}$ groups [15]. This is confirmed by two weak bands in the range of $1053-1061 \mathrm{~cm}^{-1}$ and $847-851 \mathrm{~cm}^{-1}$, assignable to the $v_{1}$ and $v_{2}$ vibrations of $\mathrm{CO}_{3}{ }^{2-}$ groups, respectively. In the BA-BUT samples synthesized at higher $\mathrm{KMnO}_{4}$ concentrations (1:0.5) and (1:1), the two bands appear at 1370 and $1500 \mathrm{~cm}^{-1}$. Whereas the band at $1500 \mathrm{~cm}^{-1}$ can be assigned to the skeletal vibrations of the aromatic ring [40], the band at 1370 $\mathrm{cm}^{-1}$ may be due to $\mathrm{O}-\mathrm{C}-\mathrm{O}$ asymmetric and symmetric stretching modes of benzoate. However, the position of this band strongly varies in dependence of the metal oxide and the binding mode [42]. In addition, a small $\mathrm{C}=\mathrm{O}$ stretching absorbance appears at $1648 \mathrm{~cm}^{-1}$. According to the review paper of Bernal et al. [15], the rare earth sesquioxides as well as the hydroxides, when exposed to atmospheric $\mathrm{CO}_{2}$ and $\mathrm{H}_{2} \mathrm{O}$ at ordinary temperature, have a strong tendency to become hydrated and carbonated, which explains the carbonate bands in the IR spectra, also in cases, where no crystalline $\mathrm{LaCO}_{3} \mathrm{OH}$ was detected by XRD.

The BA+BUT (1:1) sample was treated at $800{ }^{\circ} \mathrm{C}$ for $8 \mathrm{~h}$ in a postsynthetic step in order to investigate the further evolution of phase composition. According to Rietveld refinement of the XRD powder pattern (Fig. 9(a)), the final product contained only two phases, i.e., 43.7 wt.\% of $\mathrm{LaMnO}_{3}$ (s.g. Pnma, $a=5.446(1) \AA, b=7.742 \AA, c=5.503 \AA$ ) and 56.3 wt.\% of $\mathrm{La}_{2} \mathrm{O}_{3}$ (s.g. $P 3 m 1$, $a=3.9338(1) \AA, c=6.1223(2) \AA)$. The TEM image reveals two types of particle morphologies (Fig. 9(b)). The nanoparticles with an anisotropic, worm-like shape can be assigned to $\mathrm{La}_{2} \mathrm{O}_{3}$ and originate from the $\mathrm{La}(\mathrm{OH})_{3}$ nanofibers. The polyhedral nanoparticles represent $\mathrm{LaMnO}_{3}$ and form upon the reaction of $\mathrm{La}(\mathrm{OH})_{3}$ with $\beta-\mathrm{MnOOH}$ during calcination. Interestingly, no binary manganese oxide phases are found in this sample. The lattice fringes with a $d$-spacing of $2.77 \AA$ in the HRTEM image of such a polyhedral nanoparticle can be assigned to the 121 reflection of $\mathrm{LaMnO}_{3}$. This value does not overlap with any close equivalents of $\mathrm{La}_{2} \mathrm{O}_{3}$. Moreover, the EDX spectrum, taken from the region with polyhedral nanoparticles, shows the presence of strong 
manganese lines, whose intensity is comparable to the intensities of La and O lines (Fig. 9(d)) and additionally corroborates the identification of the polyhedral nanoparticles as $\mathrm{LaMnO}_{3}$.
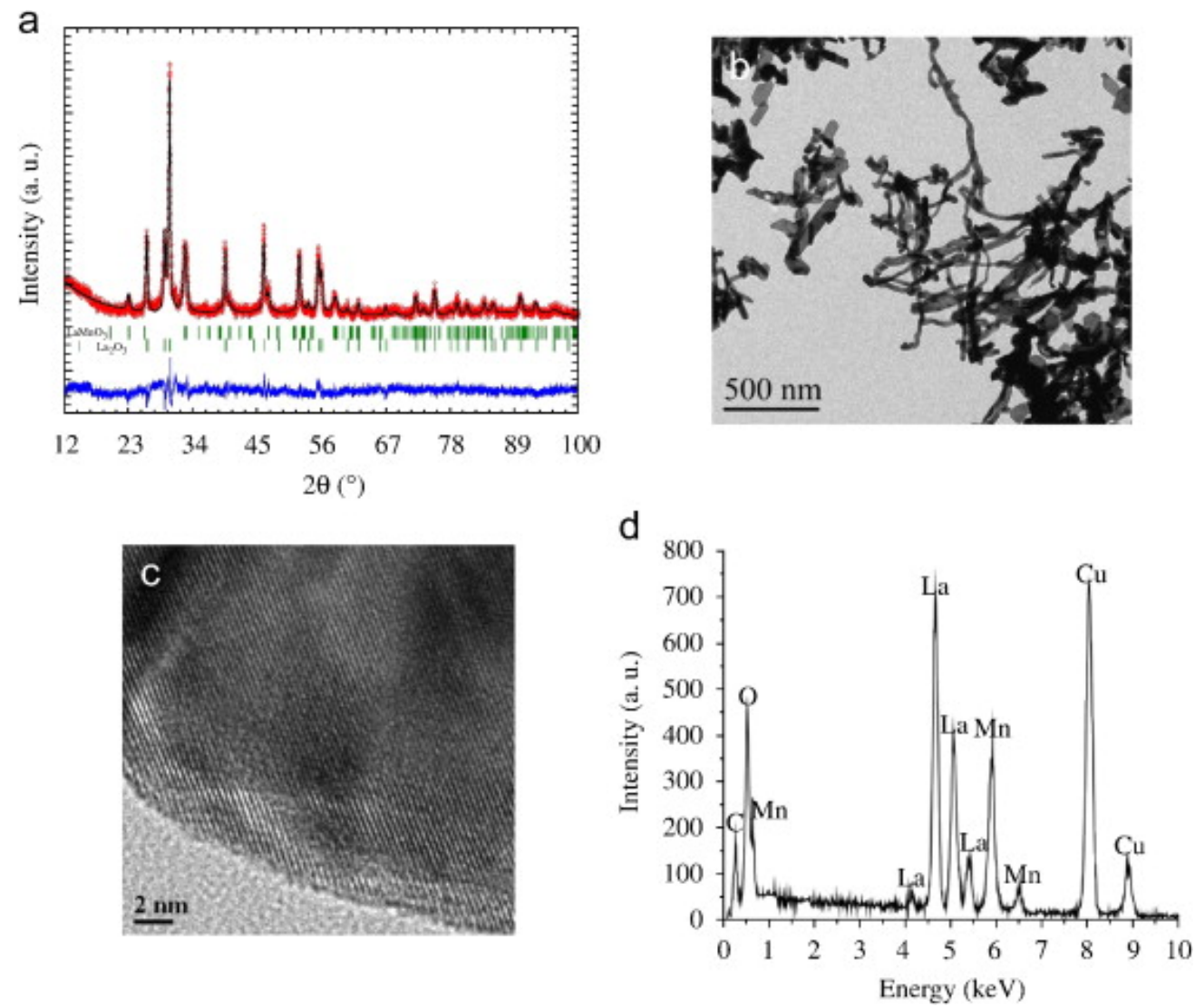

Figure 9. (a) Rietveld refinement plot for the BA+BUT (1:1) sample calcined at $800{ }^{\circ} \mathrm{C}$ for $8 \mathrm{~h}$, (b) TEM image of the same sample, (c) HRTEM image of a part of a polyhedral nanoparticle, (d) EDX spectrum taken from the region with excess of polyhedral nanoparticles.

We have shown before that nonaqueous routes to metal oxides often proceed via complex and sophisticated organic reaction steps [24], involving such diverse processes as carbon-carbon bond formation [43] and cleavage [44], or aldol condensation [45]. Already in these rather simple systems, encompassing one solvent and one metal oxide precursor, some side mechanisms take place in addition to the main reaction, leading to a number of organic byproducts. For the systems discussed here, a mixture of solvents was used, as well as $\mathrm{KMnO}_{4}$ with strongly oxidizing properties, leading to a plethora of species in the final solution. Therefore, we can just focus on some of the main routes. In both systems, no ethers were present in the final mixture, but large amounts of 2-butanol, indicating the occurrence of MeerweinPonndorf-Verley-like reduction-oxidation mechanisms, as we have described earlier (Fig. 10(a)) [43] and [45]. The concurrent oxidation of the isopropoxy ligands leads to acetone, coordinated in its enol tautomer, which induces aldol condensation with another ketone species (most probably, this would be 2-butanone as solvent as shown in Fig. 10(b)), simultaneously leading to the formal release of water in the course of the condensation reaction. In fact, especially in the BA+BUT (1:0.5) sample, containing smaller amounts of $\mathrm{KMnO}_{4}$, significant quantities of higher $\alpha, \beta$-unsaturated ketones, in particular 4-methyl-3-hexen-2-one, were found, confirming the assumption that mainly aldol condensation processes are the driving force for hydroxide formation. 


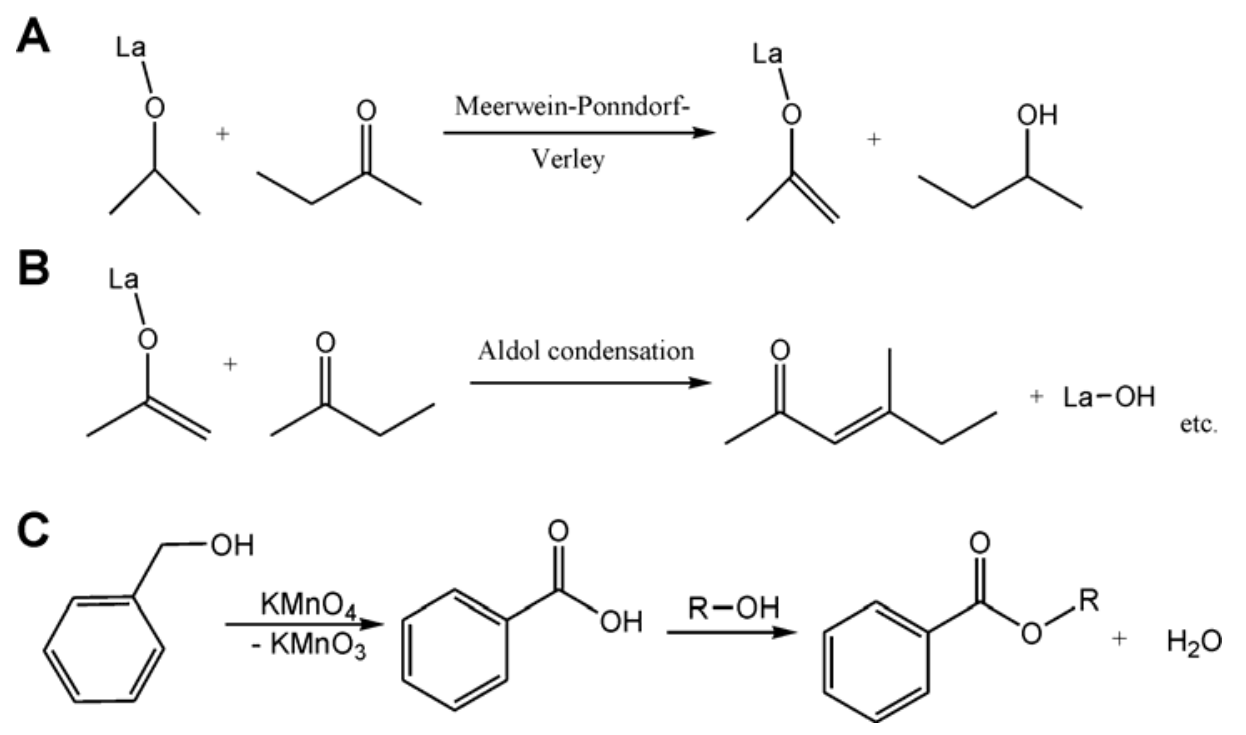

Figure 10. Proposed reaction pathways involving (a) Meerwein-Ponndorf-Verley-like reductionoxidation; (b) aldol condensation leading to the formation of a metal hydroxide species, and (c) oxidation of benzyl alcohol to benzoic acid by permanganate, followed by ester condensation and release of water.

In the case of the samples with higher amounts of $\mathrm{KMnO}_{4}$, however, additionally the presence of benzoate species like benzyl benzoate was detected. Based on these results we infer that benzyl alcohol is oxidized to benzoic acid by the permanganate, and then undergoes condensation to the ester under (formal) release of water, as illustrated in Fig. 10(c). This mechanism is clearly preferred compared to aldol condensation and leads to faster release of water and hence a more rapid growth of the nanoparticles, also in form of hydroxides. The acicular shape of the lanthanum hydroxide nanocrystals can be explained by complexation of benzoate species selectively to specific faces of the lanthanum hydroxide crystal. We have to point out that the addition of benzoic acid to the initial reaction mixture does not result in the crystallization of anisotropic lanthanum hydroxide nanoparticles, presumably due to instant esterification of benzoic acid with benzyl alcohol. Obviously, benzoic acid has to be formed in situ and parallel to the growth of the inorganic nanocrystals to fulfill its role as shape-controlling agent. The oxidation of benzyl alcohol to benzoate or benzaldehyde during nanoparticle growth often leads to the formation of particle morphologies with reduced dimensionality such as nanolayers [46] or nanowires [47]. However, it must be mentioned that the obtained reaction solutions possessed intricate composition, and thus also other mechanisms, such as decarboxylation leading e.g., to diphenylmethane, or reactions involving $\mathrm{C}-\mathrm{C}$ bond formation steps, cannot be excluded at the present stage of investigation.

\section{Conclusions}

The nonaqueous sol-gel reaction between lanthanum(III) isopropoxide and potassium permanganate in benzyl alcohol, 2-butanone and their equivolume mixture leads to formation of lanthanum hydroxide as main phase. In dependence of the molar ratio of the inorganic precursors and of the solvent used, various morphologies of $\mathrm{La}(\mathrm{OH})_{3}$ nanoparticles were formed. In a 1:1 vol. mixture of benzyl alcohol and 2-butanone and for a molar $\mathrm{La}(\mathrm{O} i \mathrm{Pr})_{3}$-to- $\mathrm{KMnO}_{4}$ ratio of 1:1 and 1:0.5, the $\mathrm{La}(\mathrm{OH})_{3}$ produced exhibits the shape of long nanofibers, while further decreasing the $\mathrm{KMnO}_{4}$ concentration results in shorter nanorods with smaller cross-sections, i.e., with decreasing amount of $\mathrm{KMnO}_{4}$, also the anisotropy of the particle morphology decreases. This observation can be explained by the fact that the acicular shape of the $\mathrm{La}(\mathrm{OH})_{3}$ nanocrystals is presumably induced by the complexation of benzoate species, formed upon oxidation of benzyl 
alcohol by permanganate, selectively to all crystal faces of $\mathrm{La}(\mathrm{OH})_{3}$ except the 001 facet. Phasepure samples containing only $\mathrm{La}(\mathrm{OH})_{3}$ nanofibers were obtained in the $\mathrm{BA}+\mathrm{BUT}$ mixture at a $\mathrm{La}(\mathrm{O} i \mathrm{Pr})_{3}$-to- $\mathrm{KMnO}_{4}$ ratio of $1: 0.5$. In this case, the nanofibers are well-crystalline with the growth direction along [001]. Postsynthetic thermal treatment of the BA+BUT (1:1) sample at $800{ }^{\circ} \mathrm{C}$ for $8 \mathrm{~h}$ yielded $\mathrm{LaMnO}_{3}$ and $\mathrm{La}_{2} \mathrm{O}_{3}$ nanoparticles without any other binary manganese oxide phases. The results after calcination are in good agreement with a recently published work by Vazquez-Vazquez and Lopez-Quintela, who presented a detailed study on the nonaqueous synthesis of doped and undoped lanthanum manganite nanoparticles, however with nearly spherical particle morphology [48].

\section{Acknowledgment}

We thank the Max Planck Society for the financial support. Furthermore, we express our gratitude to Dr. Jürgen Hartmann for EDX measurement, Mrs. Rona Pitschke for SEM and cross-sectional TEM analyses, and Mr. Laemthong Chuenchom for technical assistance with the FT-IR spectrometer.

\section{References}

[1] G.S. Yi, B.Q. Sun, F.Z. Yang, D.P. Chen, Y.X. Zhou and J. Cheng, Chem. Mater. 14 (2002), p. 2910.

[2] B.M. Tissue, Chem. Mater. 10 (1998), p. 2837.

[3] A.R. Strzelecki, P.A. Timinski, B.A. Helsel and P.A. Bianconi, J. Am. Chem. Soc. 114 (1992), p. 3159.

[4] J.N. Huiberts, R. Griessen, J.H. Rector, R.J. Wijnaarden, J.P. Dekker, D.G. de Groot and N.J. Koeman, Nature 380 (1996), p. 231.

[5] C. Platas-Iglesias, L.V. Elst, W.Z. Zhou, R.N. Muller, C. Geraldes, T. Maschmeyer and J.A. Peters, Chem. Eur. J. 8 (2002), p. 5121.

[6] P. Schuetz and F. Caruso, Chem. Mater. 14 (2002), p. 4509.

[7] H. Meyssamy, K. Riwotzki, A. Kornowski, S. Naused and M. Hasse, Adv. Mater. 11 (1999), p. 840.

[8] N. Imanaka, K. Okamoto and G.Y. Adachi, Angew. Chem. Int. Ed. 41 (2002), p. 3890.

[9] A. Slagtern, Y. Schuurman, C. Leclercq and X. Verykios, J. Catal. 172 (1997), p. 118.

[10] E. Ordonez-Regil, R. Drot, E. Simoni and J.J. Ehrhardt, Langmuir 18 (2002), p. 7977.

[11] S. Irusta, L.M. Cornaglia and E.A. Lombardo, Mater. Chem. Phys. 86 (2004), p. 440.

[12] T.L. Van, M. Che, J.M. Tatibouet and M. Kermarec, J. Catal. 142 (1993), p. 18.

[13] S. Daniele and L.G. Hubert-Pfalzgraf, J. Sol-Gel Sci. Technol. 35 (2005), p. 57.

[14] S. Daniele, L.G. Hubert-Pfalzgraf and J. Vaissermann, Polyhedron 22 (2003), p. 127.

[15] S. Bernal, F.J. Botana, R. Garcia and J.M. Rodriguez-Izquierdo, React. Solids 4 (1987), p. 23.

[16] J.H. Lunsford, Catal. Today 6 (1990), p. 235.

[17] X. Wang and Y. Li, Angew. Chem. Int. Ed. 41 (2002), p. 4790.

[18] X. Wang, X. Sun, D. Yu, B. Zou and Y. Li, Adv. Mater. 15 (2003), p. 1442.

[19] C. Hu, H. Liu, W. Dong, Y. Zhang, G. Bao, C. Lao and Z.L. Wang, Adv. Mater. 19 (2007), p. 470.

[20] F. Bouyer, N. Sanson, M. Destarac and C. Gerardin, New J. Chem. 30 (2006), p. 399. 
[21] M. Niederberger, G. Garnweitner, N. Pinna and G. Neri, Prog. Solid State Chem. 33 (2005), p. 59.

[22] M. Niederberger, G. Garnweitner, J. Buha, J. Polleux, J. Ba and N. Pinna, J. Sol-Gel Sci. Technol. 40 (2006), p. 259.

[23] G. Garnweitner and M. Niederberger, J. Am. Ceram. Soc. 89 (2006), p. 1801.

[24] M. Niederberger and G. Garnweitner, Chem. Eur. J. 12 (2006), p. 7282.

[25] L.B. McCusker, R.B. Von Dreele, D.E. Cox, D. Louer and P. Scardi, J. Appl. Cryst. 32 (1999), p. 36.

[26] J. Rodriguez-Carvajal, FULLPROF-A program for Rietveld Refinement, Laboratorie Leon Brillouin, CEASaclay, France, 2000.

[27] P. Thompson, D.E. Cox and J.B. Hastings, J. Appl. Cryst. 20 (1987), p. 79.

[28] O. Bricker, Am. Mineral. 50 (1965), p. 1296.

[29] R.A. Young, The Rietveld Method, Oxford University Press, Oxford (1993).

[30] R. Hill and C.J. Howard, J. Appl. Cryst. 20 (1987), p. 467.

[31] I. Djerdj and A.M. Tonejc, J. Alloys. Compd. 413 (2006), p. 159.

[32] A. Gajović, I. Djerdj, K. Furić, D. Su, A. Tonejc, A.M. Tonejc, S. Musić and R. Schlögl, J. Am. Ceram. Soc. 89 (2006), p. 2196.

[33] S. Kumar, M. Ade and T. Nann, Chem. Eur. J. 11 (2005), p. 2220.

[34] B. Fultz and J.M. Howe, Transmission Electron Microscopy and Diffractometry of Materials, Springer, Heidelberg (2001).

[35] X. Ma, H. Zhang, Y. Ji, J. Xu and D. Yang, Mater. Lett. 58 (2004), p. 1180.

[36] Z. Wang, L.L. Daemen, Y. Zhao, C.S. Zha, R.T. Downs, X. Wang, Z.L. Wang and R.J. Hemley, Nat. Mater. 4 (2005), p. 922.

[37] M.B. Salem, B. Yangui, G. Schiffmacher and C. Boulesteix, Phys. Status Solidi A 87 (1985), p. 527.

[38] H. Cölfen and M. Antonietti, Angew. Chem. Int. Ed. 44 (2005), p. 5576.

[39] G. Busca and V. Lorenzelli, Mater. Chem. 7 (1982), p. 89.

[40] M. Caravati, J.-D. Grunwaldt and A. Baiker, Phys. Chem. Chem. Phys. 7 (2005), p. 278.

[41] A. Tocchetto and A. Glisenti, Langmuir 16 (2000), p. 6173.

[42] C.A. Koutstaal and V. Ponec, Appl. Surf. Sci. 70/71 (1993), p. 206.

[43] M. Niederberger, G. Garnweitner, N. Pinna and M. Antonietti, J. Am. Chem. Soc. 126 (2004), p. 9120.

[44] N. Pinna, G. Garnweitner, M. Antonietti and M. Niederberger, J. Am. Chem. Soc. 127 (2005), p. 5608.

[45] G. Garnweitner, M. Antonietti and M. Niederberger, Chem. Commun. (2005), p. 397.

[46] N. Pinna, G. Garnweitner, P. Beato, M. Niederberger and M. Antonietti, Small 1 (2005), p. 112.

[47] J. Polleux, A. Gurlo, N. Barsan, U. Weimar, M. Antonietti and M. Niederberger, Angew. Chem. Int. Ed. 45 (2006), p. 261.

[48] C. Vazquez-Vazquez and M.A. Lopez-Quintela, J. Solid State Chem. 179 (2006), p. 3229. 